$\begin{array}{llll}\text { Submitted } & : 29.09 .2020 \\ \text { Accepted: } & : 02.12 .2020 & \\ \text { Year } & : \text { December 2020 Volume: } 1 \text { Issue: } 2 \\ \text { DOI } & : 10.47333 / \text { modernizm.2020265881 }\end{array}$

Gülderen Görenek ${ }^{1}$

\section{JOMOPS}

JOURNAL OF MODERNISM AND POSTMODERNISM STUDIES

\section{MODERN SANAT \\ MODERN SANAT}

Öz

1860-1960 yılları arasında yüz yıllık bir dönemi kapsayan modern sanatta, natüralizmden uzak bir anlayışla doğaya yaklaşılmıştır. Modernizmle gelen yabancılaşmaya karşı sanatçıların tek sığınak alanı sanat olmuş, "sanat için sanat" mottosuyla işlevsellik önemsenmiş ve her türlü süs olgusu bertaraf edilmiştir. Hep yeniye ulaşma arzusuyla resimde yüzey, biçim ve renk önemsenmiş ve öze varma isteği içinde temel formlar değer kazanmıştır. Modern sanatta tuval yüzeyi ve boya, geleneksel sanatın tersine bir anlayışla sahiplenilen ve hatta öne çıkarılan unsurlar olmuştur. Cleement Greenberg'e göre ilk modern sanatçı Edouard Manet'dir. Sanatçı resim yüzeyini izleyiciye göstermekten çekinmemiş ve onun önderliğinde ilerleyen Empresyonistler açık havada ışığın peşine düşerek artık hazır, tüpe girmiş boyayı, olduğu gibi ham haliyle kullanmışlardır. Cezanne ise tuvalin yatay dikeyliğini vurgulama adına biçimlerini deforme etmekten kaçınmamış, gerçekliğin ardındaki özü, geometrik form yardımıyla yapıda aramıştır. Derinliğin iki boyuta indirgenerek yüzeye çekildiği ve adına soyut espas denilen modern sanat anlayışında, kullanılan biçimler doğa taklidinden uzaktır. Mimesisin (taklit) terk edildiği yaklaşımda form, soyutlama yoluyla stilize ya da deforme edilmekte ve paralel düzlemler oluşturacak şekilde yan yana ya da art arda parçalanarak yerleştirilmektedir. Üretimin ve yaşantının, Fordist üretim anlayışıyla parçalara bölündüğü bir süreçte fragman estetiğinin modern sanatın dili olması da bir tesadüf değildir. Yine modern sanat içinde görülen gerçeklikten tamamen koparak ruhsal deneyimlerin, saf duygu yoğunluklarının aktarımına giden sanatçılar, doğadan tamamen koparak metafizik bir evrene, soyut sanata varmışlardır.

Postmodern sanatı anlamak için öncelikle modern sanatın iyi kavranması gerektiği düşünülmektedir. Çalışmada, Modern Döneme ait resim sanatı akımları, analitik bir bakış açısı ve sürece etki ederek, akışı kökten değiştirmiş örnek resimlerle ele alınmıştır. Bu çalışma ile onlarca akıma sahip modern sanatın temeli ve bu temel doğrultusunda ortaya çıkan akımların kolaylıkla anlaşılması amaçlanmıştır. Çalışmada nitel araştırma yöntemi kullanılmıştır.

Anahtar Kelimeler: Modern Dönem, Modern, Modern Sanat, Akım, Yüzey, Biçim, Renk.

\title{
MODERN ART
}

\begin{abstract}
In modern art covering a century between 1860-1960, nature was approached with an understanding far from naturalism. Against the alienation that came with modernism, art has been the only shelter for the artists putting functionality in the center with the motto "art is for art" and disgarded all kinds of ornaments. With the desire to reach new, the surface, shape and color in painting have been cared for, and basic forms have gained value in the desire to reach the essence. In modern art, the canvas surface and paint have been elements that are embraced and even highlighted with an understanding contrary to traditional art. According to Cleement Greenberg, Edouard Manet was the first Modern artist. The artist did not hesitate to show the painting surface to the viewer, and the Impressionists, who proceeded under his leadership, followed the light in the open air and used the ready-made, tubed paint in its raw form. On the other hand, Cezanne did not hesitate to deform the forms in order to emphasize the horizontal verticality of the canvas, and sought the essence behind reality in the structure with the help of geometric forms. In the modern art understanding, where the depth is reduced to two dimensions and drawn to the surface and called abstract space, the forms used are far from imitation of nature. In the approach where mimesis (imitation) is abandoned, the forms are stylized or deformed through abstraction and placed side by side or successively fragmented to form parallel planes. It is no coincidence that fragment aesthetics is the language of Modern Art in a process where production and life are fragmented with the Fordist understanding of production. The artists, who completely broke off from the reality seen in modern art and went to the transfer of spiritual experiences and pure emotional intensities, came to a metaphysical universe, abstract art, by completely breaking away from nature.
\end{abstract}

\footnotetext{
${ }^{1}$ Doçent, Resim, Çanakkale Onsekiz Mart Üniversitesi, gulderengorenek@gmail.com, https://orcid.org/00000002-9561-1925.
} 
In order to understand postmodern art, it is thought that modern art should be understood well. In the study, the painting movements of the Modern Period are discussed with an analytical perspective and sample paintings that have radically changed the flow by influencing the process. With this study, it is aimed to easily understand the basis of modern art, which has dozens of movements, and the approaches that emerged in line with this foundation. Qualitative research method was used in the study.

Keywords: The Modern Period, Modern, Modern Art, Movement, Surface, Form, Color.

\section{Giriş}

1789 Fransız Devrimi, yeni bir devlet yapılanmasına; Aydınlanma, yeni bir kültürel etkiye; 1770 yılı Sanayi Devrimi ise tarım ve hayvancılıkta ilerlemelere, nüfusta büyümeye, kırsaldan kentlere göçe ve endüstride gelişmelere neden olmuştur. Özellikle sanayileşmeyle gelen değişimler sonrasında politik ve ekonomik bunalımlar baş göstermiş bu da 1848 ve 1871 ayaklanmalarıyla sonuçlanmıştır (Harvey 39). Modernizm de tüm bu gelişmelerin ardından bir dönem özelliği göstererek ortaya çıkmıştır. Modernizm, sanayileşmeyle birlikte gelen kentsel bir olgudur ve kentleşmeyle birlikte bireyselleşme, endüstrileşme, yabancılaşma, laikleşme ve metalaşma modernizmin kapsamı içinde ele alınmaktadır.

Huns Robert Jauss'a göre modern terimi V. yüzyılda 'şimdi' anlamında Latince "modo" kelimesinden türemiştir ve modern, şimdiyi yücelterek bugünün dünden, geleceğin ise bugünden ileri olduğunu ima etmektedir (Habermas 31). Modernizmin temelinde yeniye bir tutku vardır. Yeniye olan bu tutku, sanayileşmeyle gelen tüketim kültürünün körüklediği bir yaklaşım olmuştur. Çünkü tüketim kültürüyle gelen meta toplumu hep yeniyi elde etme davranışıyla sürecin devamlılı̆g 1 için bir tampon görevi üstlenmiştir (Burger 123). Bu anlamda Walter Benjamin (131), kentli toplumun tüketim kültürünün yeni alışkanlığı olan endüstriyel lüksün icadı pasajlardan bahsetmekte ve pasajları, camlı çatılarıyla ışığı yukarıdan alan ve her iki yakasında dükkanların bulunduğu caddeyle iç mekân arası bir yer olarak tarif etmektedir. Böylece pasajlarla bulvarlar, iç mekâna dönüşmekte ve yeni kentli tip olan modern zamanların kent gezgini "flâneur" için cadde konuta dönüşmektedir. "Flaneur olgusunda aydın pazara çıkmıştır. Pazarı görmek için çıktığını sanmaktadır, ama gerçekte alıcısını bulmak için çıkmıştır," (Benjamin 39).

Baudelaire için de kalabalıklarda var olan ve gördüğü her şeyi derin bir duyarlılıkla gözlemleyen sanatçı tipi, bu kentli ortamda "flâneur" olmalıdır. Hatta Baudelaire (207), sanatçı sıfatı için “...çoğu hünerli kaba saba insanlar, katıksız zanaatkârlar, köyün zekileri dar kafalılarıdır.” diyerek yermiş ve modern yeni sanatçı tipini, dünya insanı olarak nitelendirdiği Bay G üzerinden tarif etmiştir. Baudelaire, Bay $\mathrm{G}$ için bu dünyanın manevi işleyişine ilişkin ince bir duyarlılığa sahip dünya insanı oluşuna ad koyarken sanatçı yerine ona, "dandy" demiştir.

\section{Modern Sanat}

Modernizm, resim sanatında 1860-1960 yıllarını kapsayan bir dönem olarak ortaya çıkmıştır. Resim sanatında bu başlangıç 1830 Romantizm ve Gustave Courbet'ye kadar taşınsa da 1860 Edouard Manet ile başlayıp 1900'lerde estetik bir dil kazanan ve 1945'lerde olgunlaşip 1960'ta sonlanan modernizm, yüz yıllık bir süreci kapsamıştır (Şimşek). Resim sanatında bu yüz yıllık süreçte modernizmin getirmiş olduğu yabancılaşmaya karşı sanatçıların tek sığınak alanı sanat olmuştur. Sanat için sanat mottosuyla işlevselliğin önemsendiği ve her türlü süs olgusunun bertaraf edildiği modernizmde hep yeni olma arzusuyla resimde geleneksel anlayıştan uzaklaşılmış ve o zamana kadar saklanması gereken bir unsur olarak görülen resim yüzeyi tam tersine öne çıarılmıştır. Bu bağlamda modern sanatta; yüzey, biçim ve renk önemli olmuş ve sanatta öze varma isteği, temel formları değerli kılmıştır. Modern anlayışın en önemli eleştirmenlerinden biri olan Clement Greenberg, modern sanat estetiğini şu dört madde ile sıralamıştır. Modern sanat:

1. İçerikten çok biçime önem verir. ("Bu aslında ortamın (medium) gelişmesi ve soyutlamaya indirgenmesi anlamına gelir.") 2. Biçim, yüzey, renk önemsenen önemli unsurlardır. 3. Estetik etki başlıca unsur olarak politik etki ya da toplumsal anlamın önünde durur. 4. İzleyen sanatsal bir uğraş içinde olur. Günlük yaşamın getirdiği her türlü karmaşadan uzaktır (Whitham ve Pooke 17-18). 
Modern Sanatta tuval yüzeyi ve boya geleneksel sanattın tersine bir anlayışla sahiplenilen ve öne çıkarılan unsurlar arasında yer almıştır. Bu esasta Edouard Manet, resim yüzeyini ve boyayı çeşitli geleneksel tekniklerle saklamadan izleyiciye olduğu gibi göstermekten çekinmemiştir. Bu özelliğinden ötürü Greenberg resim sanatında ilk modern olarak Manet'yi ve ilk modern resim olarak sanatçının 1863'de yapmış olduğu "Olimpia'yı" göstermiştir (Greenberg 357). Sanatçı, gerek "Kırda Öğle Yemeği'nde" gerek "Olimpia'da” gündelik hayattan olay ve insanları seçerek izleyicileri şok duygusu içinde bırakacak resimler üretmiştir (Şekil 1 ve 2.). Örneğin "Olimpia'da" dağınık beyaz çarşaf üzerinde davetkâr yarı çıplak yatan kadın, artık kendi gerçekliği dışında herhangi bir şeye imada bulunmamaktadır. Bu resimde boyanın boya olarak gösterildiği ve bir genelev kadınının müssterisinden gelen çiçeği kabul ettiği modern zamana ait bir an resmedilmiştir.

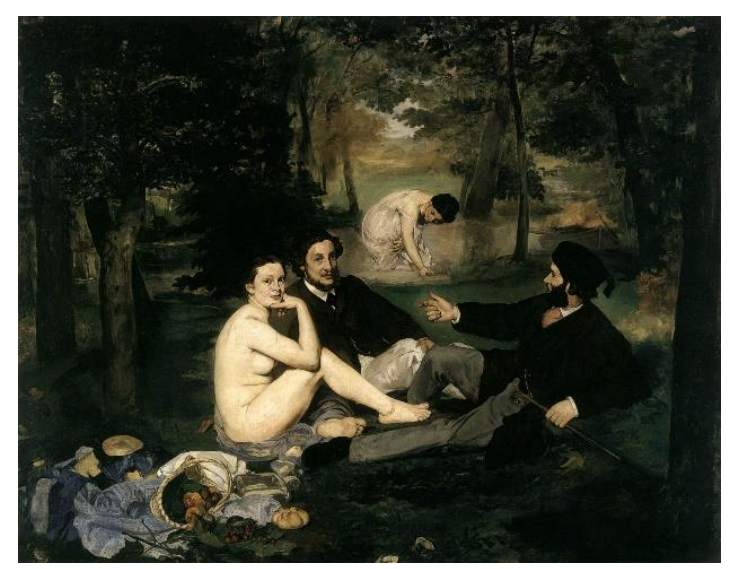

Şekil 1. Edouard Manet, 1863, Kırda Öğle Yemeği, 208 x $265,5 \mathrm{~cm}$

Manet'nin önderliğinde ilerleyen Empresyonistler boyayı, tüpten çıkmış ham haliyle beyaz astarlı tuvallere kullanmışlardır. Böylelikle zaten 1şı̆̆ın peşinde olan Empresyonistler için resimler daha 1şıklı olmuştur. Fotoğraf makinesinin olanaklarından, Japon estamplarından ve Michel Eugène Chevreul'ün "Renklerin Eş Zamanlı Kontrastı Kanunu" çalışmasından etkilenen Empresyonistler, doğadan duyumlarıyla edindikleri izlenimleri resimlerine aktarmışlardır. En önemli Empresyonist sanatçı Claude Monet'dir. Bir süre Argenteuil'in açık havasında Manet ile birlikte de çalışan Monet, hayatı boyunca Empresyonist resimler yapmıştır. Yağlı boyanın, endüstrileşerek tüp içine girmesi, bu dönemde Monet gibi diğer ressamlara da açık havada çalışma fırsatı vermesi açısından önemli olmuştur.

Monet resimlerinde günün herhangi bir saatinde 1şı̆̆ , yakalamak istemiş ve 1şıkla birlikte değişen renkleri resimlerine yansıtmıştır. Sanatçı, açık havada çalışmanın olanağı içinde kesik firça vuruşları kullanırken resimlerinde formlar hacimlerini kaybederek yassılaşmıştır. Hatta resimlerde dağılan formlar, ancak belli bir mesafeye ihtiyaç duyarak anlam kazanmaktadır. Monet, Empresyonist anlayışın temelinde 1şıkla birlikte değişen gerçekliği yakalama adına günün başka zamanlarına ait görünüşleri tekrarlayarak birçok seri resimler yapmıştır. Sanatçının seri resimlerinden biri olan "Saman Yığınları" (Şekil 3) daha sonra Wassili Kandinsky gibi soyut resmin öncüsüne de ilham olmuştur. 


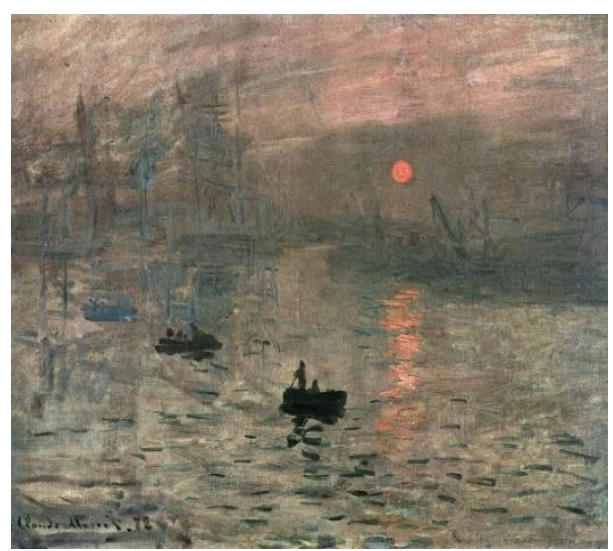

Şekil 3. Claude Monet, 1872, İzlenimGündoğumu, 48 x $63 \mathrm{~cm}$

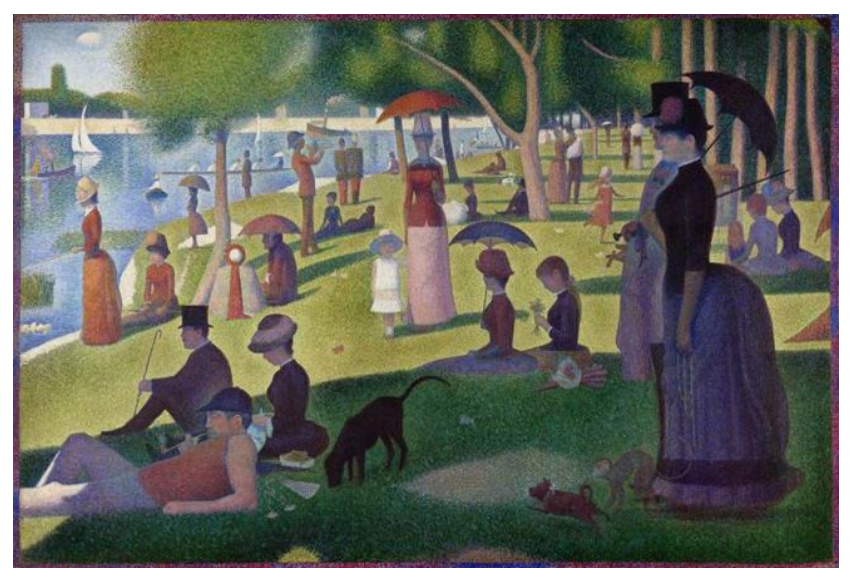

Şekil 4. Georges Seurat, 1884-86, Grande Jatte Adasi'nda Bir Pazar Öğleden Sonra, 207,5 x $308 \mathrm{~cm}$

Neo-empresyonist akımın öncü ressamlarından biri olan George Seurat, renk üzerine Chevruel ve Ogden Rood'un bilimsel çalışmalarını resim alanına taşımıştır. Renkleri palette karıştırıp renk yoğunluklarını azaltmak yerine tüpten çıktığı gibi ham, rengin en yoğun haliyle tuvale noktalar halinde yan yana sürmüş ve ara renklerin optik yanılsamayla izleyenin gözünde oluşmasını sağlamıştır. Sanatçı, "Grande Jatte Adası'nda Bir Pazar Öğleden Sonra" (Şekil 4) resmini 1884-86 y1lları arasında iki yılda bitirmiştir. Bu resmi planlarken onlarca büyük ebatta taslak resimler yapmıştır. Bu resimde sanatçı hem renk üzerine bilimsel bulguları sanata taşırken hem de modern bir kentlinin hafta sonlarını nasıl geçireceklerine dair bir hayat önerisi de sunmaktadır. Ancak sanatçı, modern sanat anlayışı içinde yüzey, renk ve biçim kaygılarını bir kenara bırakmadan resmini oluşturmaktadır. Modern sanatta önemli bir unsur olan tuvalin yatay ve dikeyliğini vurgulamak için resmi biteviye dolaşan boyalı tuşlarla renkli bir çerçeve oluşturmuş̧tur.

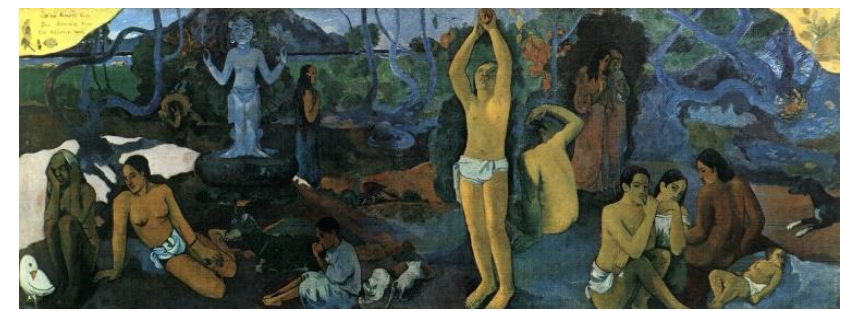

Şekil 5. Paul Gauguin, 1897, Nereden Geldik, Kimiz, Nereye Gidiyoruz, 139,1 x $374,6 \mathrm{~cm}$

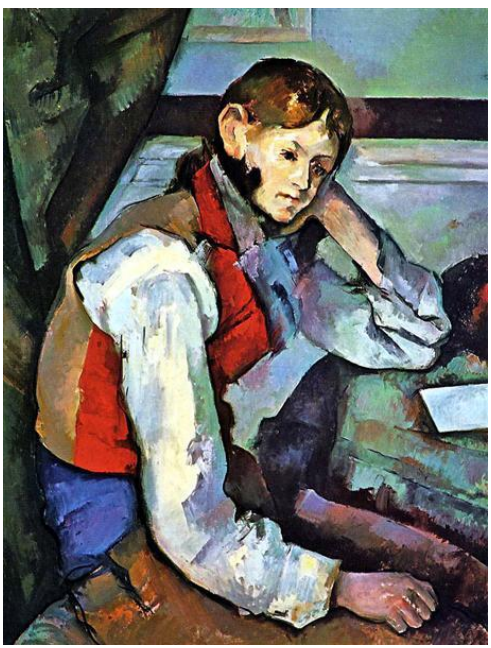

Şekil 7. Paul Cezanne, 1889, Kırmızı Yelekli Çocuk, Tuval üzerine yağlı boya, $64,5 \times 80 \mathrm{~cm}$

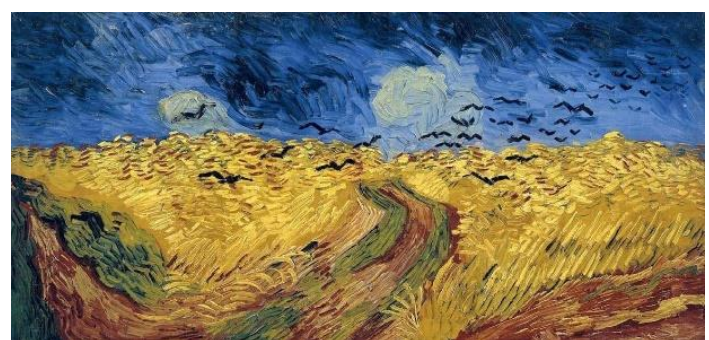

Şekil 6. Vincent Van Gogh, 1890, Buğday Tarlası, $50,5 \times 103 \mathrm{~cm}$ 
Paul Gauguin, Vincent van Gogh ve Paul Cézanne, Post-empresyonist sanatçılardır. Paul Gauguin, Modern Dönem'de primitif sanatlara karşı duyulan ilginin etkisiyle Avrupa dışına çıkarak Tahiti'ye yerleşmiş burada ilkel hayatın saflığı içinde öze varmak istemiştir (Şekil 5). Resimleriyle Fovizm ve Renk Alan Resmine öncülük etmiştir. Yine diğer Post-empresyonist sanatçı Vincent van Gogh kendine özgü atak fırça vuruşu ve renk kullanımıyla modern sanatın önemli sanatçılarından biri olmuş ve resimleri Ekspresyonist sanatçılara ilham vermiştir (Şekil 6). Paul Cezanne ise Kübizm'e öncülük etmiştir. Sanatçı kendi anlayışını oluştururken doğaya duyular yardımıyla varmış ve böylece yakaladığ $\breve{1}_{1}$ gerçekliğin ayakları yere basarken rengin ve biçimin ahengine ulaşmıştır (Read 205). Ancak Cezanne, Empresyonist sanatçıların duyumlara bağlı uçucu form anlayışını reddetmiş, küp, küre, prizma, silindir gibi temel biçimler aracılıyla doğayı akıl yoluyla kavrayarak yapı arayışına girişmiştir. Sanatçı, (Şekil 7) resimlerinde modülasyon tekniğiyle tuvalin yatay dikeyliğini vurgulamak için biçimlerini deforme etmekten çekinmemiştir (Greenberg 357). Sanatçı, modern sanat anlayışını kavrayışıla özellikle Kübizm ve soyut sanatın gelişimine öncülük etmiştir.

Ekspresyonizm yine 20. yüzyılın başlarında ortaya çıkan akımlardan biri olmuştur. Van Gogh'un açmış olduğu yolda duygularıyla ilerleyen sanatçılar, Almanya'da 1905'te Dresden'de Die Brücke Grubu'nu kurmuşlardır ki grup daha sonra çalışmalarını Berlin'e taşımıştır. 1913 yılında grup dağılana kadar Ekspresyonist sanatçılar doğayı, kendilerinde uyandırdığg duygular temelinde resimlemişlerdir (Şekil 8). Akımın diğer grubu ise 1911 yılında Münih'de kurulan Der Blaue Reiter grubu olmuştur. Wassili Kandinsky grubun kurucusu ve önemli sanatçısı olarak soyut resim denemelerine girişmiştir. Der Blaue Reiter (Mavi Binici) sanatçıları, grubun adında da geçen mavi rengine ve at figürüne, Franz Marc gibi diğer grup üyeleriyle birlikte mistik anlamlar da yükleyerek resimlerinde sıklıkla kullanmışlardır (Şekil 9 ve Şekil 10). I. Dünya Savaşı'nın başlamasıyla grup dağılmış ancak Kandinsky, rengin ve biçimin müzikle kurulmuş olan ritmik birlikteliğini duyumsattığ1 resimleriyle soyut resmin ilk ressamı olmuştur.

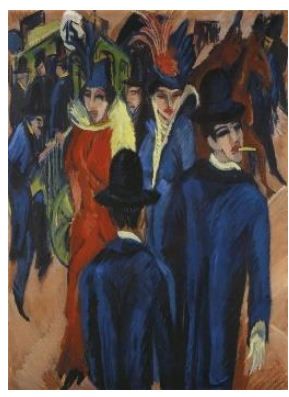

Şekil 8. Ernst Ludwig Kirchner, 1913-14, Berlin Sokağı, 121x 95 $\mathrm{cm}$

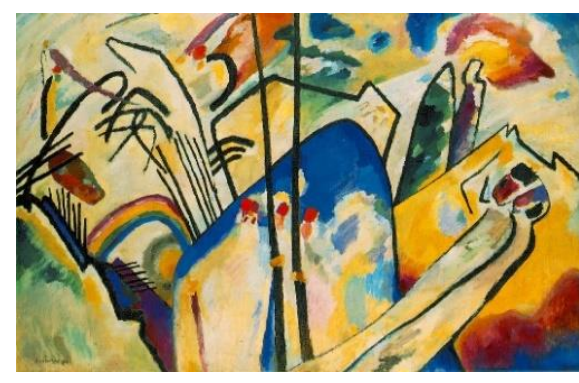

Şekil 9. Wassili Kandinsky, 1911, Kompozisyon IV, 159,5 x 250,5 cm

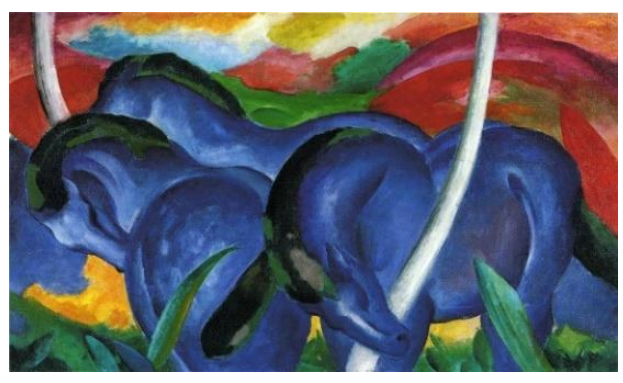

Şekil 10. Franz Marc, 1911, Büyük Mavi Atlar, $104,78 \times 181,61 \mathrm{~cm}$

Henri Matisse, 20. yüzyılda Paris'te ortaya çıkan akımlardan olan Fovizmin kurucusu ve önemli bir sanatçısı olmuştur. Neo-empresyonistlerden etkilenen sanatçı, sonrasında rengi daha atak ve yalın haliyle yüzeye sürerek renkçi bir anlayışta resimler üretmiştir. Derinliği yüzeye çekerken espası aynı değerde tuttuğu sıcak soğuk renk zitlıklarıyla yakalayan sanatçı, modern sanatın yeniye olan tutkusunu 20. yüzyılın başlarında rengi egemen kılarak ortaya koymuştur (Şekil 11). Matisse'in parlak ve atak renk kullanımındaki cesareti, Pablo Picasso için itici bir güç olurken sanatçıyı başka arayışlara sürüklemeye kaynaklık etmiştir (Şekil 12). 


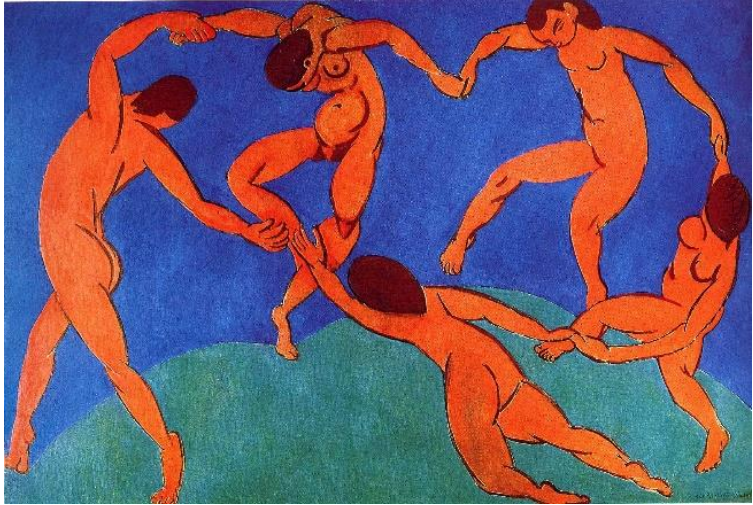

Şekil 11. Henri Matisse, 1910, Dans II, 391 x 260 cm

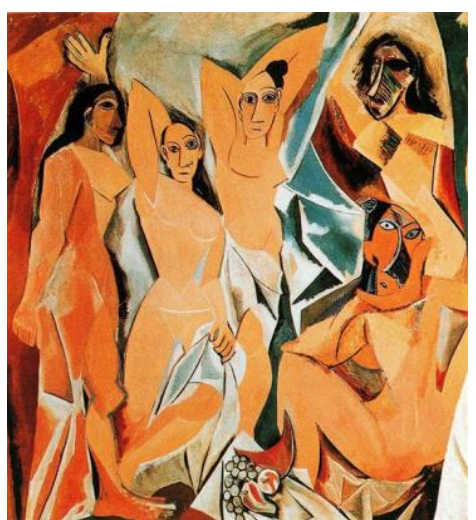

Şekil 12. Picasso, 1907,

Avignonlu Kadınlar, 243,9 x

$233,7 \mathrm{~cm}$

Pablo Picasso Matisse'den ve modern sanat anlayışından aldığı yeniye dönük ilhamı, Afrika ve İberya masklarıyla harmanlamış ve babamız dediği Cézanne'nın çizdiği yolda ilerleyerek George Braque'la birlikte 20. yüzyılın önemli akımlarından biri olan Kübizmi kuran önemli sanatçılarından biri olmuştur. Cézanne'nın temel geometrik formlarla doğadaki yapıyı görme yaklaşımını sahiplenen sanatçı, Braque'la birlikte Fransız Pireneleri'nde bir yıl sürecek çalışmalara girişmiştir. Manzara, portre ve özellikle natürmort resim türünde örnekler veren bu iki sanatçı, doğaya duyumlarla değil akıl yoluyla varmaya çalışmışlardır. "Kübizmde soyut biçimlerin oluşturduğu bir varlık düzeninde var olan salt biçimdir (Tunalı 165-166)."

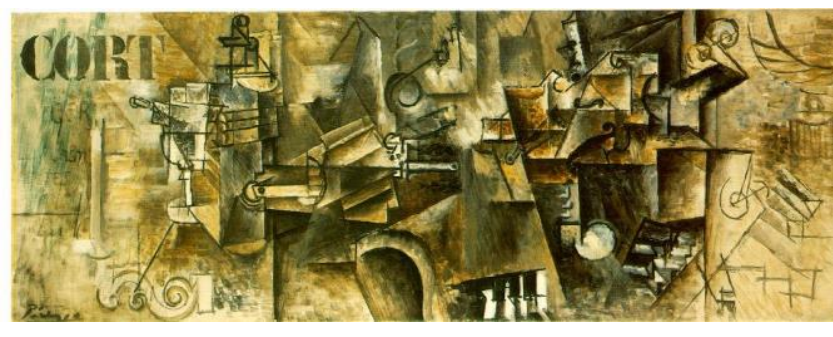

Şekil 13. Pablo Picasso, 1911, Piyano Üzerinde Natürmort

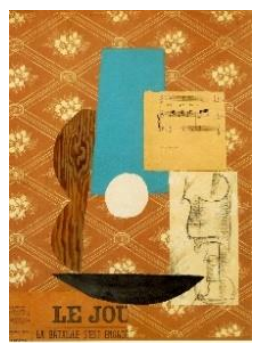

Şekil 14. Pablo Picasso, 1912, Gitar, Kâğıt, Müzik ve Şişe

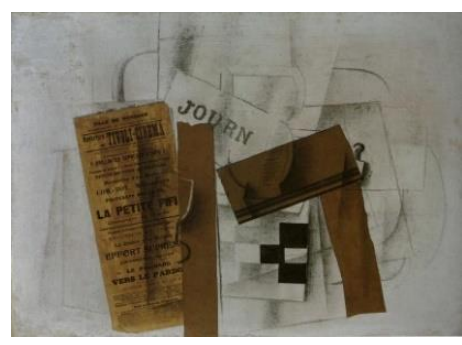

Şekil 15. George Braque, 1913, Dama Tahtas1 Tivoli Sinema, 92,3 $\mathrm{x} 65,5 \mathrm{~cm}$

Kübist anlayışta ilk olarak Analitik Kübist resimler veren sanatçılar bu yaklaşımda faklı açılardan aldıkları görüntüleri parçalara bölmüş ve üst üste ya da yan yana yerleştirerek resim yüzeyinde tüm açıları tek bir görünüşe yani tek bir ana sıkıştırmışlardır. Böylece tamamen temsil sisteminden uzaklaşılırken Einstein'nın Görelilik Kuramı'nda da bahsi geçen dördüncü boyut olan zaman kavramı resmin içine girmiştir. Sentetik Kübizmde ise zaman kavramı, başka mekân, dolayısıyla başka anlardan toplanan gazete, duvar kâğıdı ya da hasır gibi malzemelerin kolaj tekniğiyle resimde kullanılmasıyla gerçekleştirilmiştir (Şekil 13,14 ve 14). Modern sanatın en önemli eleştirmenlerinden Greenberg, Kübizm ile resimde kullanılan imgelerin artık zorlukla seçildiğini ve Batı sanatında Cimabue'den beri görülmeyen bir düzlügün varlığının Kübist yaklaşım ile resme taşındığını ifade etmiştir (Greenberg 359).

Fütürizm 1909 yılında İtalya'da etkinlik kazanmış bir akımdır. Bir grup sanatçının, Kübist form anlayışına ve modernizmle gelen makineleşmeye karşı duydukları hayranlığın göstergesi olarak ortaya çıkmıştır. Kent görüntüleri, tren istasyonları ve trenler, fabrikalar, elektrik direkleri gibi modern hayatla gelen unsurlar hayatın dinamizmini yüceltme adına Fütürist resme konu olmuştur. Dolayısıyla makineleşmenin getirmiş olduğu hız ve dinamizm bu akımda, dile getirilmesi gereken en önemli unsurdur. Akımın sanatçısı olan Umberto Boccioni 1911 yılına ait "Ruh Durumları: Uğurlamalar" (Şekil 16) adlı triptik resminde Analitik Kübist yaklaşıma ritmik hareketlerle yakaladığı dinamizmi eklemiştir. Resimde kullanılan parçalanmış ve çoğaltılmış hayatın temsili olan biçimler, saydam 
parçalar halinde üst üste yerleştirilirken nesneleri tanımak ve onları birbirinden ayırmak zorlaşmışırır (Lynton 88-89).

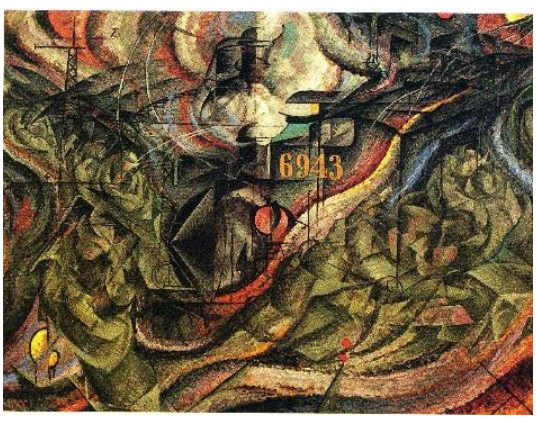

Şekil 16. Umberto Boccioni, 1911, Aklın Durumu I, Uğurlamalar, 70,5 x 96,2 cm

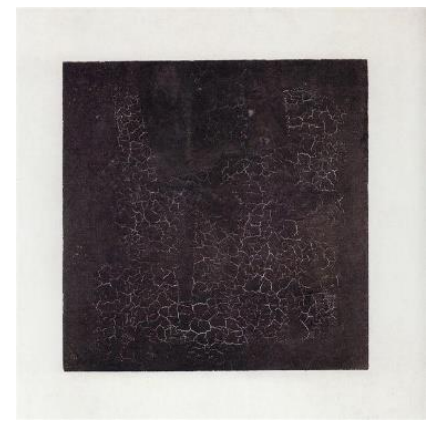

Şekil 17. Kazimir Malevich, 1915, Siyah Kare, 106 x 106 cm

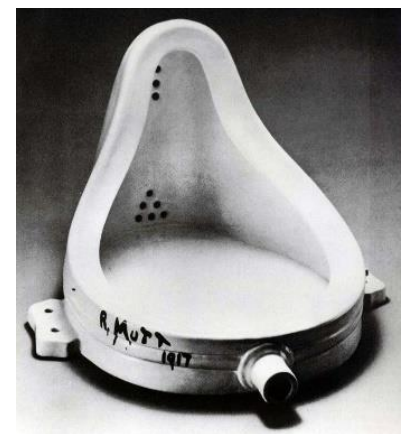

Şekil 18. Marcel Duchamp 1917, Fountain-Çeşme

Modern sanatta, Kandinsky ile başlayan soyut sanat, Kazamir Maleviç'in de başvurduğu bir modern sanat dili olmuştur (Şekil 17). Maleviç'in resim anlayışında formlar doğa taklidinden tamamen uzaktır. Hiçbir form doğada izlenebilecek bir gerçekliğe göndermede bulunmamaktadır. Süprematizm denilen bu sanat akımında, güzellik ve gerçekliğin ardındaki öz; kare, dikdörtgen, daire gibi salt geometrik formlarda aranmıştır. "Siyah Kare" (1915), saf duygunun ifade alanı olarak hiçbir şeyin resmi; resmin sıfır noktası olmuş ve Maleviç (207) tarafından şöyle ifade edilmiştir: "Kare, bilinçaltı bir biçim değil. Sezgisel aklın yaratımı. O yeni sanatın yüzü. Kare canlı bir kraliyet çocuğu. Sanatta saf yaratımın ilk adımı. Ondan önce, doğanın naif çarpıtmaları ve kopyaları vardı. Bizim sanat dünyamız yeni, nesnel olmayan, saf bir şey oldu."

Marcel Duchamp Paris'te başladığı sanat hayatına, I. Dünya Savaşı'nın patlak vermesiyle 1914'te gittiği Amerika'da devam etmiştir. 1917 yılında Amerika'da kendisinin de üye olduğu Bağımsız Sanatçılar Birliğinin ücretli sergisine R.Mutt imzasıyla göndermiş olduğu "Foundation/ Çeşme" (Şekil 18) adlı eseriyle katılmıştır. Bir nalburdan aldığı hazır yapım bir pisuarı imzalayarak ters çevirmiş ve adına "Çeşme" diyerek onu kendi bağlamından koparmıştır. Böylece Duchamp readymade/hazır nesne kavramını sanatın içine katmış ve sanatçının seçimi doğrultusunda ele alınacak sanat eserini göz ile izlenmekten akılla kavranacak bir anlama taşımıştır. Bu eser sergiye kabul edilmemiş ancak o zamana kadar devam eden sanatsal yaklaşımların akışını değiştirmiştir. Öyle ki Duchamp ve Dadaistler 20. yüzyılın en sıra dışı yaklaşımlarını gerçekleştirdikleri sanat eserleriyle günümüz sanat yaklaşımlarına halen kaynaklık etmektedir.

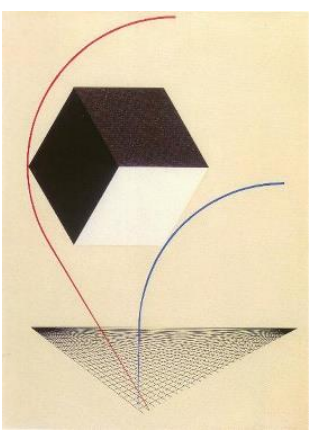

Şekil 19. El Lissitzky, 1925, Proun, Kolaj, guaj, mürekkep

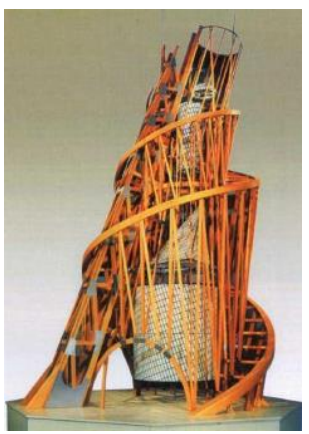

Şekil 20. Vladimir Tatlin, 1919-1920, III. Uluslararası Hareket'in modeli, Heykel

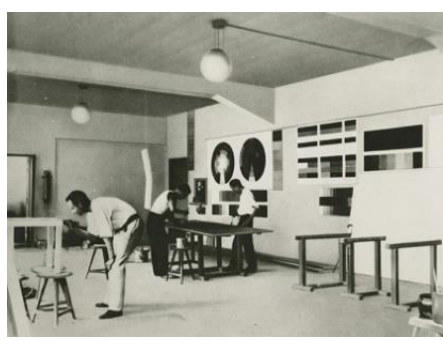

Şekil 21. Bauhaus Atölye

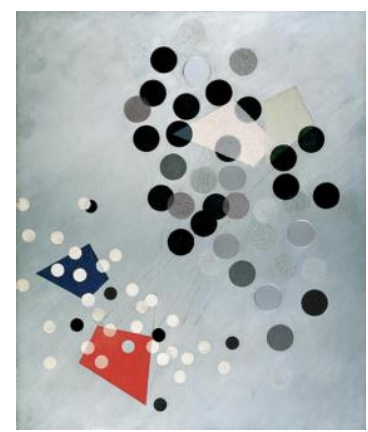

Şekil 22. Laszlo MoholyNagy, 1933, Construction AL6

1913 yılında Konstrüktivistler, yeni bir dünyanın inşasını gerekli görmüşlerdir (Şekil 19, 20 ve 22). Rusya'da 1917 Ekim Devrimi ile gelen değişimler, yeni bir dünya için sanatı da kendi bağlamından koparmış, sanatçılar, sanatı, gündelik hayatla buluşturarak işlevselliği önemli kılmışlardır. Sanatçılar kullanışlı tasarım ürünlerini geniş bir tabanın hizmetine sunarken işleve tasarım eklemeyi amaçlamışlardır (Antmen 103). 
Bauhaus, sanat ve zanaatı buluşturan 20. yüzyllın en önemli okullarından biri olmuştur. 1919 yılında Almanya'da, Weimer kentinde kurulan ve dört yıl burada eğitimin verildiği okul, (Şekil 21) daha sonra Dessau'ya oradan da 1932'de Berlin'e taşınmış, Naziler tarafından 1933'te kapatılana kadar burada eğitime devam edilmiştir. Konstrüktivistler gibi sanat, toplum içindir yaklaşımıyla Bauhaus sanatçıları, modern hayat içinde seri üretimle herkesin evine girecek olan günlük kullanım eşyalarına bir sanatçı dokunuşu getirmek istemişlerdir. Seramik, tekstil, cam, metal, baskı gibi okul atölyelerinde endüstrinin talebi doğrultusunda tasarım prototipleri üretmişlerdir.

Hollandalı sanatçı Mondrian, doğadan edindiği izlenimleri Natüralist, Empresyonist, Puantislist, ve Fovist potada erittikten sonra 1911'de Hollanda'da açılan sergiden etkilenerek Kübist eğilimler taşıyan resimler yapmıştır. Kübizm, sanatçıda daha derin izle bırakarak onun Paris'e taşınmasına vesile olmuştur. Daha Paris'e taşınmadan önce Helena Petrovna Blavatsky'nin “Gizli Öğreti” kitabından etkilenen sanatçı, Blavatsky'nin, kurmuş olduğu Teozofi akımıyla ilgilenmiştir. I. Dünya Savaşı patlak vermeden önce Paris'ten Hollanda'ya geri dönmüş ve savaş nedeniyle dönüşünü ertelemek zorunda kalmıştır. 1917 yılında, Mondrian, De Stijl dergisi çevresinde var olan oluşuma dergi kurucusu Theo van Doesburg'un daveti ile katılmıştır.

Mondrian'nın resimlerinde temel gaye, öze ulaşma, hakikate varma edimi olmuştur. Bu esasta sanatçı, resimlerinde en temel biçim ve renkleri kullanmıştır (Şekil 23). Tuvalin beyaz yüzeyine, yine tuvalin yatay dikeyliğini, çoklu siyah şeritler yardımıyla taşımış ve kesişen şeritlerin oluşturduğu kare ya da dikdörtgen biçimlere, kırmızı, mavi, sarı gibi ana renkler ya da siyah, gri gibi nötr renkler sürmüştür.

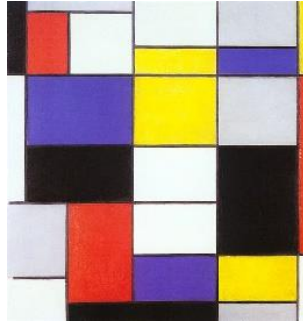

Şekil 23. Piet Mondrian, 1923, Kompozisyon A

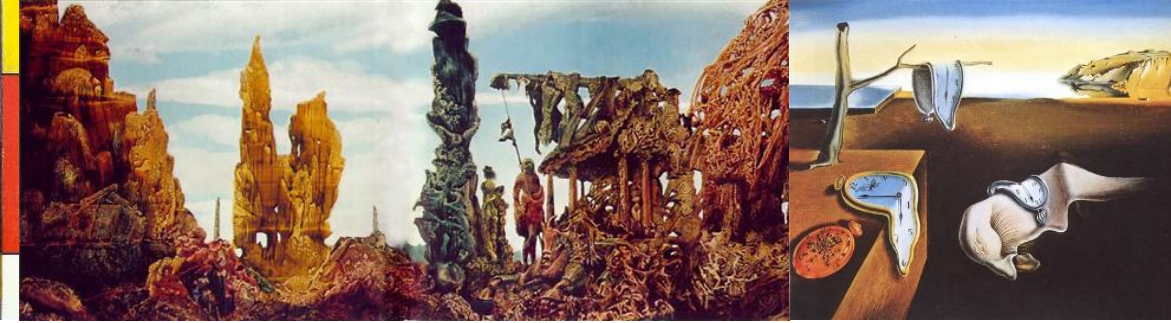

Şekil 24. Max Ernst, 1941, Yağmurdan Sonra Avrupa, 54 $\mathrm{x} 146 \mathrm{~cm}$
Şekil 25. Salvador Dali, 1931, Belleğin Azmi (Eriyen Saatler), Tuval üzerine yağl1 boya, $24,1 \mathrm{x}$ $33 \mathrm{~cm}$

Sürrealizm, 1924'te başlayıp 1939'a kadar devam etmiştir. Yine Sürrealizm, Dadaizm ve Sigmund Freud'un çalışmaları temelinde anlam kazanan bir akım olmuştur. Andre Breton I. Sürrealizm Manifestosu’nda: “... Sürrealizm şimdiye kadar görmezden gelinmiş belli çağrışım biçimlerinin üstün gerçeğini, düş kurmanın mutlak gücünü ve düşüncenin önyargısız işleyişini temel alır." demiştir (Hopkins 38-39). Tüm önyargılardan kurtularak hayal gücünü serbest bırakma adına otomatizm ve oneirizm gibi teknikleri kullanan Sürreal sanatçılar, yaratıcılığa ket vuracak her türlü otoriteden kendilerini azat etmişlerdir. Bu serbest bırakış, her türlü estetik hazır bulunuşu da içermektedir. Böylece saf yaratıcılık eylemi içinde hayaller, uyanıkken kurulan düşler, harekete geçmekte; böylece izleyen, gerçek dünyaya ait imgelerden şaşkınlık yaratıcı düşsel bir dünyaya taşınmaktadır (Şekil 24, 25).

Max Ernest akımın en önemli sanatçılarından biri olarak, kolaj, frotaj, grataj, dekalkomani ve oscillation/salınım gibi yenilikçi teknikleri resimlerinde kullanmıştır. Şekil 24'te görüldüğü üzere dekalkomani tekniğini kullanan sanatçı, yüzeye sürdüğü boyayı başka bir yüzey aracılıyla dağıtmış ve ön tasarımsız biçimler elde etmiştir. Sonrasında denetimli sürdüğü boyayla etkileyici sürreal bir dünya yaratmıştır.

1940'tan sonra sanat merkezi Paris'ten New York'a taşınmıştır. Bunun nedenlerinden biri, I. Dünya Savaşı nedeniyle Avrupa'dan Amerika'ya göç eden Duchamp, Picabia, Mondrian, Leger, Max Ernst, Dali, Chagall, Moholy-Nagy gibi sanatçıların kendileriyle birlikte Avrupa sanatını Amerika'ya taşımış olmalarıdır. Diğer bir neden ise Amerika'nın dünya üzerinde tek güç olma isteği ve bu tek güç olma politikasında sanatı bir araç olarak kullanmak istemeleridir. Soyut-dışavurumcu sanatçıları her ne 
kadar bu politikayı desteklemeseler de devlet destekli sanat yapma yaklaşımına da karşı durmamışlardır. Bu yüzden Soyut-dışavurumcu yaklaşım, Amerikan Hükümeti desteğiyle dünya ölçeğinde tanıtımı yapılan küresel bir sanat akımı olmuştur.

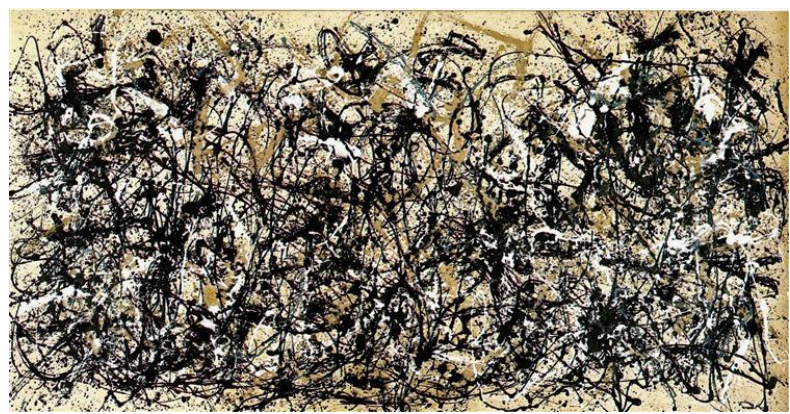

Şekil 25. Jackson Pollock, 1950, Sonbahar Ritmi (Say1 30), $105 \times 207 \mathrm{~cm}$

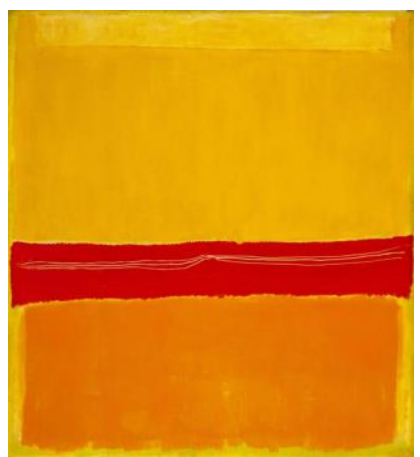

Şekil 26. Mark Rothko, 1949-50, No.5 No.22, 297 x $272 \mathrm{~cm}$

Jackson Pollock Soyut-dışavurumun önemli sanatçılarından biridir. Sanatçı yere serdiği bezlere boyayı damlatmış, sıçratmış, serpmiş ve yaptığı resme kendi beden hareketlerinin yaratmış olduğu ritmi de katarak çalışmalarını oluşturmuştur (Şekil 25). Bu esasta Pollock kendi sanatını açıklarken resminin şövaleden gelmediğini ifade etmiştir. Resimlerini katı bir yüzeye ihtiyaç duyduğu için yere serdiğini ve çevresinde gezinebildiğini böylece resmin içine rahatlıkla girebildiğini söylemiştir. Sanatçı, resim yaparken bilindik geleneksel malzemeler yerine sopa, mala ve bıçak gibi materyaller kullanmıştır. Damlatmaya uygun akıcı boya ya da cam kırıkları veya kumla ağırlaştırılmış kalın boyayı tercih etmiştir (Pollock 610).

Yine Soyut-dışavurumculuğun içinde ele alınan başka bir yaklaşımda Renk Alan Resmi ve bu akımın en önemli sanatçılarından biri de Mark Rothko'dur. Köklerini Gauguin'e kadar götürülebilen bu yaklaşımda, sanatçı geniş ebatta tuttuğu resimlerine kat kat şeffaf sürdüğü monokrom renklerin titreşimlerinden izleyen üzerinde ruhsal etkiler bırakmayı amaçlamaktadır (Şekil 26).

1960'ta Pop Sanat, Amerika ve İngiltere'de birbirinden bağımsız gelişen ancak aynı kaygıları güden bir akım olmuştur. Amerika'da akımın önemi sanatçıları; Andy Warhol, Roy Lichtenstein, Tom Wesselmann, James Rosenquist, Claes Oldenburg, Edward Ruscha sayılabilir. Duchamp'in hazır nesne işleri üzerinden sanatı kavramsal boyuta taşıdığı yoldan Pop sanatçıları ilerlemiş, kitle kültürünü ve ürünlerini resimlerinin konusu yapmıştır. Özellikle Andy Warhol pop kültürünü yansıttığ 1 işleriyle dikkat çekmektedir. Makine gibi resim yapmak istiyorum diyen sanatçı, resimlerinde herhangi kişisel iz bırakmamaya özen göstererek seri işler yapmış bu seri işlerinde özellikle pop sanatçıları, devlet adamları gibi ikon karakterleri yanı sıra yaşanılan yıllara ait Campbell Çorbası Kutuları gibi popüler nesnelerin serigrafi baskılarını almıştır (Şekil 27, 28).

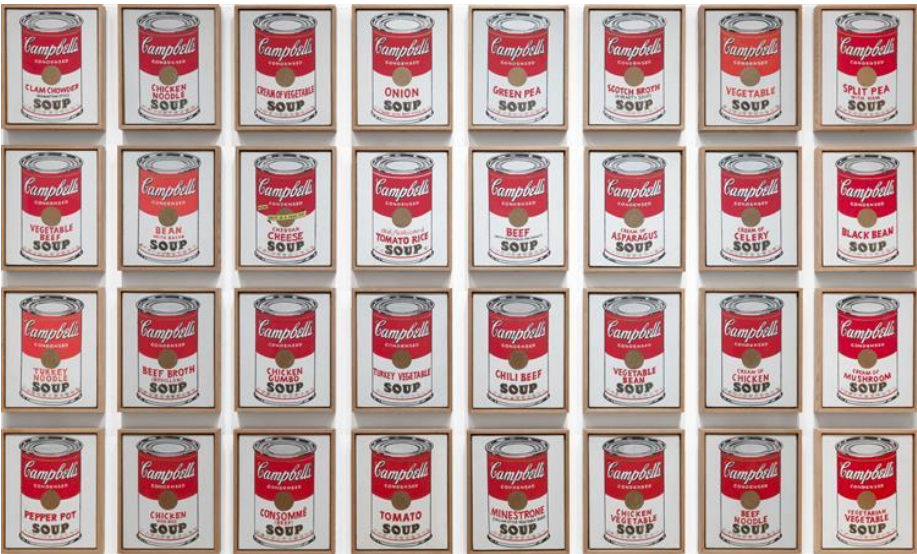

Şekil 27. Andy Warhol, 1962, Campbell Çorbası Kutular,

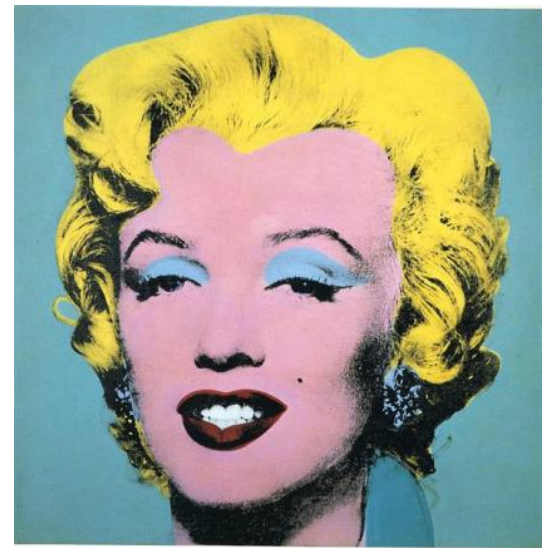

Şekil 28. Andy Warhol, 1964, Marilyn, 
Optik Sanat, 1960'l yıllarda ortaya çıkan ve sanata, bilim ve teknoloji de katan bir yaklaşım olmuştur. İzleyiciden sanatlarını anlama konusunda herhangi bir hazır bulunmuşluk beklemeyen Op Art sanatçıları, eserlerinde göz yanılsaması yaratacak buluşlarla izleyicinin görsel algısını yönetmişlerdir. Akımın önemli sanatçılarından biri olan Victor Vasarely, 1957 yılında yapmış olduğu "Vega" resminde (Şekil 29) iki boyutlu yüzeyde hem derinliğin hem de hareketin yaratılabileceğini, diğer Op Art sanatçıları gibi siyah beyaz karşıtlığı, renk kontrastları ve merkez noktaların farklı düzenlenmesiyle gerçekleştirmiştir (Tuğal 96).
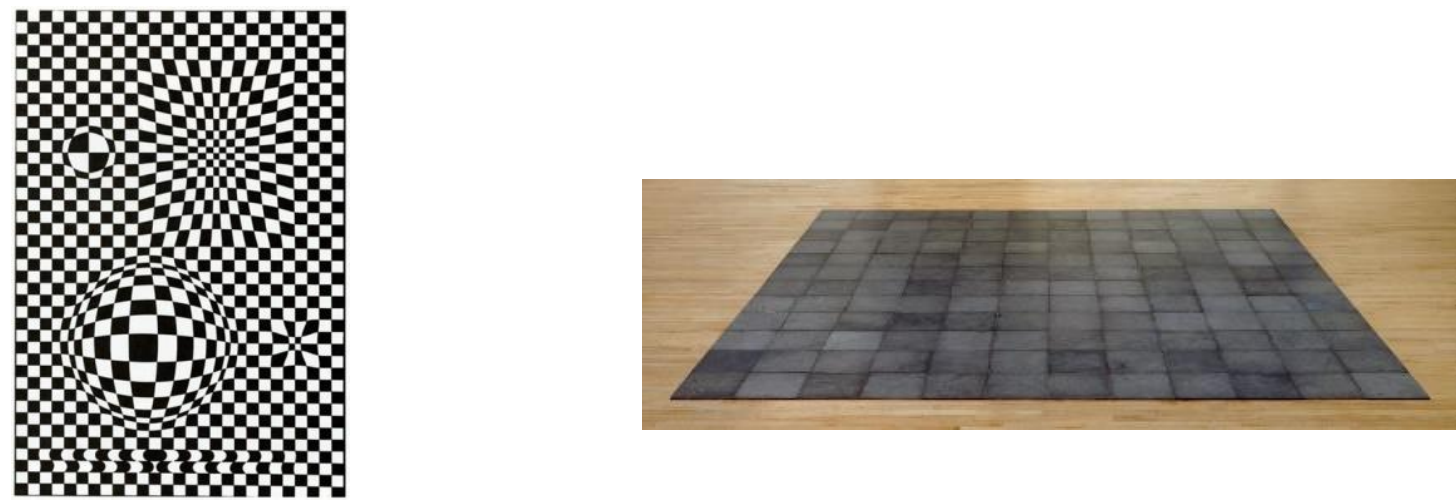

Şekil 29. Victor Vasarely, 1957, Vega

Şekil 30. Carl Andre, 1969, 144 Magnezyum Kare

1960 yılında Minimalizm ile modern sanatta, başka bir sürece girilmiştir. Artık izleyici, eser önünde sanatçısının öznel yaklaşımını taşıyacak herhangi bir izle karşılaşmamaktadır. Minimalizm'de; kare, dikdörtgen, silindir, küre gibi temel formların kullanıldığı ve mekân olanaklarının işin içine katıldığı üç boyutlu çalışmalar görülmektedir. Daha çok heykel alanında izlenen eserlerde endüstriyel malzemeler kullanılmıştır (Ateş 2314).

1950'lerden itibaren Minimalist çalışmalar içine giren Carl Andre, 1969'da 30,48 x 30.48 santimetrelik tek bir birim magnezyum ve kurşun plakayı 144 plaka daha çoğaltarak oluşturduğu düzenlemeyi, izleyicinin üzerinden geçmesine izin verecek şekilde mekânın zeminine yerleştirmiştir. "Magnezyum Kare", alüminyum, çelik, çinko, bakır ve kurşundan oluşan başka altı seriden biridir. Sanatçı plakalar üzerinde öznel iz olacak hiçbir değişiklik yapmadan ham haliyle kullanmıştır. Çalışma 1969'da New York Dwan Gallery'de sergilenmiş̧ir (Hodge).

\section{Sonuç}

1960'lardan sonra büyük ivme kazanan sanatta değişim, ilk köklerini Duchamp ile atmıştır. Özellikle 1972'de Minoru Yamasaki'nin Pruitt-Igoe toplu konutlarının dinamitle ortadan kaldırılması postmodern denen başka bir süreci başlatmıştır. Piyasa, toprak rantı, küreselleşme ve metropolleşen kent olgusu sonucu 1980'den sonra postmodern, uluslararası bir boyut kazanmıştır. Eklektizm, kolaj, montaj, üst üste bindirilmiş alıntı imgeler, ayakları üzerinde duran kültürel nesneden çok çökmüş bir zaman ve mekân duygusu, melezleşme, pastiş, ironi ve parodi, postmodern sanatın dili olmuştur.

Postmodern denen dili doğru anlamlandırmak için "post” öncesi modernizme baktığımızda modernizmle gelen yabancılaşmaya karşı sanatçıların tek sığınak alanı sanat olmuş, sanat için sanat mottosuyla işlevsellik önemsenmiş ve her türlü süs olgusu bertaraf edilmiştir. Art arda gelen akımlarla hep yeniye ulaşma arzusuyla resimde yüzey, biçim ve renk önemsenmiş ve öze varma isteği içinde temel formlar değer kazanmıştır. Modern sanatta tuval yüzeyi ve boya, geleneksel sanatın tersine bir anlayışla sahiplenilen ve hatta öne çıkarılan unsurlar olmuştur.

Modern, mahareti sanatçıda biten ve belli kurallar ölçüsünde ilerleyen bir sanat anlayışına sahipken, postmodern tam tersi olarak belli kurallar ölçüsünde ilerlemenin yerine belli bir üsluplaşma özelliği görüldüğü takdirde tam aksi hareket edebilen bir tavır göstermekte ve izleyiciden işe karş1 anlam çıkarma becerisi isteyecek noktada son derece talepkâr olmaktadır. Modern sanatta öze ulaşma çabası ve inanc1, formu, saf biçim ve renge indirgerken, postmodern böyle bir öze ulaşma çabası içine hiç girmemektedir. Hatta böyle bir özün varlığına da inanmamakta ve sanatın bir form işi olduğu fikrini tümden reddetmektedir. 
$\mathrm{Bu}$ çalışmayla onlarca akıma sahip modern sanatın temeli ve bu temel doğrultusunda ortaya çıkan akımların kolaylıkla anlaşılması amacıyla başta sanat öğrencilerine, sanat severlere ve araştırmacılara modern sanatın temelinin ne olduğuna dair araştırmalarında kaynaklık etmesi temenni edilmektedir.

\section{KAYNAKÇA}

Breton, Andre. Resimde Yeni Gerçekçilik, eds. Charles, Harrisson, ve Paul Wood. Sanat ve Kuram 1900-2000 Değişen Fikirler Antolojisi, Çev. Sabri Gürses. İstanbul: Küre, 2011.

Antmen, Ahu. Sanatçılardan Yazılar ve Açıklamalarla 20. Yüzyılın Batı Sanatında Akımlar, İstanbul: Sel, 2014.

Ateş, K. Selvihan. Baskıresimleri ile Minimalist Bir Sanatç1: Richard Serra, DOI: 10.7816/idil-06-3611 Cilt 6, Sayı 36, Volume 6, Issue 36 idil, 2017: 2311-2323. Web. 8 Eylül 2020.

Baudelaire, Charles. Modern Hayatın Ressamı, Çev. Ali Berktay. İstanbul: İletişim, 2009.

Benjamin,Walter, Pasajlar, Çev. Ahmet Cemal. İstanbul: Yapı Kredi, 2002.

Burger, Peter. Avangar Kuramı, Çev. Erol Özbek. İstanbul: İletişim, 2009.

Şimşek, Ali. "Modernizm ve Sanat" Online video clip. YouTube. YouTube, 25 Ekim 2018 Web. 10 Temmuz 2020.

Hodge, David. “Carl Andre 144 Magnesium Square 1969”, 2014. Web. 9 Ağustos 2020.

Greenberg, Clement. Modernist Resim, Haz. Enis Batur. Modernizmin Serüveni Bir “Temel Metinler" Seçkisi 1840-1990, İstanbul: Yapı Kredi, 2002.

Habermas, Jurgen. “Modernlik: Tamamlanmamış Bir Proje”, Dipnot Dergisi, Say1 1 (2010): 29-41.

Harvey, David. Postmodernliğin Durumu, Çev. Sungur Savran. İstanbul: Metis, 2010.

Hopkins, David. Dada ve Gerçeküstücülük, Çev. Suat Kemal Angı. İstanbul: Dost, 2004.

Lynton, Norbert. Modern Sanatın Öyküsü, Çev. Cevat, Çapan, ve Sadi Öziş. İstanbul: Remzi, 1991.

Maleviç, Kazimir. Kübizm ve Fütürizmden Süprematizme: Resimde Yeni Gerçekçilik, eds. Charles, Harrisson, ve Paul Wood. Sanat ve Kuram 1900-2000 Değişen Fikirler Antolojisi, Çev. Sabri Gürses. İstanbul: Küre, 2011.

Pollock, Jackson. İki Açıklama, Resimde Yeni Gerçekçilik, eds. Charles, Harrisson, ve Paul Wood. Sanat ve Kuram 1900-2000 Değişen Fikirler Antolojisi, Çev. Sabri Gürses. İstanbul: Küre, 2011.

Read, Herbert. Sanatın Anlamı, Çev. Güner, İnal, ve Nuşin Asgari. İstanbul: İş Bankası Kültür Yaymlar1, 1960.

Tuğal, Sibel Avcı. Oluşum Sürecinde Op Art, İstanbul: Hayal Perest, 2018.

Tunalı, İsmail. Felsefenin Işı̆̆ında Modern Resim, İstanbul: Remzi Kitabevi, 1992.

Whitham, Graham, ve Pooke Grant. Çağdaş Sanatı Anlamak, Çev. Tufan Göbekçin. İstanbul: Optimist, 2013.

Whitham, Graham, ve Pooke Grant. Sanatı Anlamak, Çev. Tufan Göbekçin. İstanbul: Hayalperest, 2018.

\section{GÖRSEL KAYNAKÇA}

Şekil 1. Edouard Manet, 1863, Kırda Öğle Yemeği, 208 x 265,5 cm, https://www.wikiart.org/en/edouard-manet/the-luncheon-on-the-grass-1863

Şekil 2. Edouard Manet, 1863, Olympia, 130,5 x $190 \mathrm{~cm}$, https://www.wikiart.org/en/edouardmanet/olympia-1863 
Şekil 3. Claude Monet, 1872, İzlenim-Gündoğumu, 48 x 63 cm, https://www.wikiart.org/en/claudemonet/impression-sunrise

Şekil 4. Georges Seurat, 1884-86, Grande Jatte Adası'nda Bir Pazar Öğleden Sonra, 207,5 x 308 cm, https://www.wikiart.org/en/georges-seurat/study-for-a-sunday-on-la-grande-jatte-1885

Şekil 5. Paul Gauguin, 1897, Nereden Geldik, Kimiz, Nereye Gidiyoruz, 139,1 x 374,6 cm, https://www.wikiart.org/en/paul-gauguin/where-do-we-come-from-what-are-we-where-arewe-going-1897

Şekil 6. Vincent Van Gogh, 1890, Buğday Tarlası, 50,5 x 103 cm, https://www.wikiart.org/en/vincent-van-gogh/wheatfield-with-crows-1890

Şekil 7. Paul Cezanne, 1889, Kırmızı Yelekli Çocuk, Tuval üzerine yağlı boya, 64,5 x $80 \mathrm{~cm}$, https://www.wikiart.org/en/paul-cezanne/boy-in-a-red-vest-1889

Şekil 8. Ernst Ludwig Kirchner, 1913-14, Berlin Sokağ1, 121x 95 cm, https://www.wikiart.org/en/ernst-ludwig-kirchner/berlin-street-scene-1914

Şekil 9. Wassili Kandinsky, 1911, Kompozisyon IV, 159,5 x 250,5 cm, https://www.wikiart.org/en/wassily-kandinsky/composition-iv-1911

Şekil 10. Franz Marc, 1911, Büyük Mavi Atlar, 104,78 x 181,61 cm, https://www.wikiart.org/en/franz-marc/the-large-blue-horses-1911

Şekil 11. Henri Matisse, 1910, Dans II, 391 x 260 cm, https://www.wikiart.org/en/henrimatisse/dance-ii-1910

Şekil 12. Picasso, 1907, Avignonlu Kadınlar, 243,9 x 233,7 cm, https://www.wikiart.org/en/pablopicasso/the-girls-of-avignon-1907

Şekil 13. Pablo Picasso, 1911, Piyano Üzerinde Natürmort, https://www.wikiart.org/en/pablopicasso/still-life-on-the-piano-cort-1911

Şekil 14. Pablo Picasso, 1912, Gitar, Kâğıt, Müzik ve Şişe, https://www.wikiart.org/en/pablopicasso/guitar-sheet-music-and-wine-glass-1912

Şekil 15. George Braque, 1913, Dama Tahtas1 Tivoli Sinema, 92,3 x 65,5 cm, https://www.wikiart.org/en/georges-braque/checkerboard-tivoli-cinema-1913

Şekil 16. Umberto Boccioni, 1911, Aklın Durumu I, Uğurlamalar, 70,5 x 96,2 cm, https://www.wikiart.org/en/umberto-boccioni/states-of-mind-i-the-farewells-1911

Şekil 17. Kazimir Malevich, 1915, Siyah Kare, 106 x 106 cm, https://www.wikiart.org/en/kazimirmalevich/black-square-1915

Şekil 18. Marcel Duchamp 1917, Fountain-Çeşme, https://www.artsy.net/article/artsy-editorialduchamps-urinal-changed-art-forever

Şekil 19. El Lissitzky, 1925, Proun, Kolaj, guaj, mürekkep, https://www.wikiart.org/en/ellissitzky/proun

Şekil 20. Vladimir Tatlin, 1919-1920, III. Uluslararas1 Hareket'in modeli, Heykel, https://www.wikiart.org/en/vladimir-tatlin/model-of-the-monument-iii-international-1920

Şekil 21. Bauhaus Atölye, https://www.kulturservisi.com/p/sanat-ve-zanaat-okulu-bauhaus/

Şekil 22. Laszlo Moholy-Nagy, 1933, Construction AL6, https://www.wikiart.org/en/laszlo-moholynagy/construction-al6

Şekil 23. Piet Mondrian, 1923, Kompozisyon A, https://www.wikiart.org/en/pietmondrian/composition-a-1923

Şekil 24. Max Ernst, 1941, Yağmurdan Sonra Avrupa, 54 x 146 cm, https://blog.singulart.com/en/2019/09/13/europe-after-the-rain-ii-an-abstract-apocalypticlandscape/ 
Şekil 25. Salvador Dali, 1931, Belleğin Azmi (Eriyen Saatler),Tuval üzerine yağlı boya, 24,1 x $33 \mathrm{~cm}$ https://www.wikiart.org/en/salvador-dali/the-persistence-of-memory-1931

Şekil 25. Jackson Pollock, 1950, Sonbahar Ritmi (Say1 30), 105 x 207 cm, https://www.wikiart.org/en/jackson-pollock/not_detected_185311

Şekil 26. Mark Rothko, 1949-50, No.5 No.22, 297 x 272 cm, https://www.wikiart.org/en/markrothko/no-5-no-22

Şekil 27. Andy Warhol, 1962, Campbell Çorbası Kutular, https://www.wikiart.org/en/andywarhol/campbells-soup-cans-1962

Şekil 28. Andy Warhol, 1964, Marilyn, https://www.wikiart.org/en/andy-warhol/marilyn-1

Şekil 29. Victor Vasarely, 1957, Vega, https://www.wikiart.org/en/victor-vasarely/vega-1957

Şekil 30. Carl Andre, 1969, 144 Magnezyum Kare, https://www.tate.org.uk/art/artworks/andre-144magnesium-square-t01767 